\title{
VIABILIDADE DO SÊMEN DO JUNDIÁ, Rhamdia quelen, ARMAZENADO SOB REFRIGERAÇÃO
}

\author{
Semen Viability of Jundia, Rhamdia quelen, Storage \\ Under Refrigeration
}

\author{
Paulo César Falanghe Carneiro ${ }^{1}$ \\ Márcio Saporski Segui ${ }^{2}$ \\ César Roberto Ióris Filho ${ }^{3}$ \\ Jorge Daniel Mikos ${ }^{4}$
}

\section{Resumo}

A preservação do sêmen sob refrigeração é uma técnica simples e que se encaixa como possível alternativa para a utilização racional do sêmen de peixes que apresentam potencial para a aqüicultura comercial ou para programas de repovoamento. O presente trabalho avaliou a viabilidade do sêmen do jundiá, Rhamdia quelen, armazenado em refrigerador doméstico. Machos de jundiá foram submetidos à indução hormonal com extrato hipofisário para coleta de sêmen e posterior armazenamento sob refrigeração $\left(5,7^{\circ} \mathrm{C}\right)$ por 12 dias. Durante o período experimental, foram determinadas a motilidade do sêmen em microscópio óptico e a taxa de sobrevivência dos espermatozóides em extensões de sêmen corados com coloração supravital. Também foi realizado teste de fertilização pela mistura de $10 \mu \mathrm{l}$ de sêmen de machos em $5 \mathrm{~g}$ de óvulos obtidos de um grupo de fêmeas, possibilitando a avaliação do sêmen fresco até aquele armazenado por 12 dias. A taxa de fertilização foi determinada 15-20 horas após a união dos gametas, tendo os ovos permanecidos em minincubadoras com volume útil de 1,5 L. Durante 12 dias foi observada redução significativa na motilidade do sêmen armazenado. Foi registrada também redução gradativa na porcentagem de espermatozóides vivos no decorrer do período, iniciando em 74,5\% e finalizando em 15,5\% após 12 dias. Apesar das dificuldades encontradas na condução do ensaio para a determinação da taxa de fertilização, foi possível constatar taxa de fertilização superior a 50\% após 12 dias de armazenamento do sêmen, mesmo sendo registradas redução na motilidade e sobrevivência. O presente trabalho apresenta o potencial da técnica de armazenamento do sêmen do jundiá sob refrigeração e reforça a necessidade de mais estudos nessa área visando à otimização dos procedimentos de reprodução induzida em laboratório e redução dos custos de produção de alevinos.

Palavras-chave: Reprodução; Peixe; Indução hormonal.

1 Professor do Curso de Zootecnia (CCAA, PUCPR) e Coordenador Científico do LAPEP/PUCPR (Laboratório de Pesquisa e Piscicultura). E-mail: paulo@cpatc.embrapa.br

2 Professor do Curso de Medicina Veterinária - CCAA, PUCPR.

3 Acadêmico do Curso de Zootecnia - CCAA, PUCPR.

4 Engenheiro Agrônomo do LAPEP, PUCPR. 


\section{Abstract}

Semen storage under refrigeration is a simple technique which fits well as an alternative for later use for reproduction of fish species with potential for aquaculture industry or enhancement programs. This study evaluated the viability of jundia, Rhamdia quelen, semen kept into domestic fridge. Twenty four Jundia males were submitted to hormonal induction with pituitary extract for semen withdrawing and further storage under $5.7^{\circ} \mathrm{C}$ for 12 days. During the experimental period spermatozoa motility was determined under optic microscopy and spermatozoa survival rate was registered using supra vital coloration method. Fertilization rate was also determined in 1.5-L incubators using a mixture of $10 \mu \mathrm{l}$ of semen of each male and $5 \mathrm{~g}$ of eggs from a group of females. Semen motility decayed significantly during the experimental period as well as did the spermatozoa survival rate, reducing from 74.5 to $15.5 \%$ at the day 12. Despite the problems occurred during the fertilization assay, values above $50 \%$ were found after 12 days of the semen storage. This study presents the high potential of using jundia semen after storage under temperature above freezing and states the necessity of further studies on this issue to optimize fish reproduction procedures under laboratory conditions and reduce costs of fingerling production.

Keywords: Reproduction; Fish; Hormonal induction.

\section{Introdução}

A piscicultura vem crescendo e se destacando em diversos estados brasileiros. O cultivo de jundiá, Rhamdia quelen (Siluriformes, Pimelodidae), apresenta-se crescente, principalmente na Região Sul do Brasil, em função da sua rusticidade ao manejo e resistência a baixas temperaturas. $\mathrm{Na}$ região metropolitana de Curitiba, a criação dessa espécie vem apresentando resultados positivos, contribuindo para o desenvolvimento econômico e social de muitos produtores rurais e adequandose aos atuais enfoques ambientais, por tratar-se de uma espécie nativa dos rios da região (CARNEIRO et al., 2002).

Observações a campo mostram que o macho desta espécie prepara-se precocemente durante o período reprodutivo produzindo sêmen num momento inicial em que as fêmeas ainda não estão aptas à reprodução. No final do período reprodutivo, quando facilmente encontram-se fêmeas prontas para o processo de indução hormonal, observa-se redução na proporção de machos liberando sêmen, bem como na quantidade de sêmen produzido por indivíduo. A questão do sincronismo entre machos e fêmeas durante o período de reprodução também é comum em outras espécies de peixes. Segundo Fogli da Silveira et al. (1990), durante a reprodução artificial do pacu, Piaractus mesopotamicus, os machos não apresentam resposta sincrônica com as fêmeas.

Técnicas de preservação de sêmen sob baixas temperaturas vêm sendo utilizadas há tempos em várias espécies de peixes, não apenas para contornar problemas de sincronismo entre machos e fêmeas, como também para otimizar os traba- lhos de reprodução induzida em laboratório e reduzir os custos de produção (NINHAUS-SILVEIRA et al., 2002; HORVÁTH et al., 2003; MARQUES; GODINHO, 2004; LINHART et al., 2005). A preservação do sêmen sob refrigeração é uma alternativa simples e de baixo custo para a utilização do sêmen por períodos de tempo maiores, podendo trazer benefícios ao processo de reprodução induzida do jundiá (MARQUES; GODINHO, 2004). O presente trabalho teve como objetivo avaliar a viabilidade do sêmen do jundiá armazenado sob refrigeração.

\section{Material e métodos}

Vinte e quatro machos adultos de jundiá provenientes de viveiros de terra de $400 \mathrm{~m}^{2}$ destinados à manutenção de reprodutores foram transferidos para 2 tanques de $2 \mathrm{~m}^{3}$ do LAPEP-PUCPR (Laboratório de Pesquisa e Piscicultura da P2ontifícia Universidade Católica do Paraná). Durante seis dias foram coletados diariamente quatro machos que foram submetidos à indução hormonal pela injeção intramuscular de extrato hipofisário (dose única: $0,5 \mathrm{mg} / \mathrm{kg}$ ) para posterior coleta de sêmen por pressão abdominal. Nesse período, 24 alíquotas de sêmen foram coletadas e acondicionadas em frascos escuros fechados hermeticamente, sendo mantidos sob refrigeração em geladeira $\left(5,7 \pm 1,2^{\circ} \mathrm{C}\right)$.

No sexto dia (meio do período experimental), foram feitas desovas de cinco fêmeas (688 \pm 268 g) submetidas à indução hormonal com extrato hipofisário $\left(1 .^{\mathrm{a}}\right.$ dose: $0,5 \mathrm{mg} / \mathrm{kg} ; 2 .^{\mathrm{a}}$ dose: 5 $\mathrm{mg} / \mathrm{kg}$; intervalo entre aplicações: 12 horas; deso- 
va: 7-8 horas após a segunda aplicação; temperatura da água: $26^{\circ} \mathrm{C}$ ) para a realização do teste de fertilização do sêmen. Todos os óvulos retirados foram misturados homogeneamente num único recipiente para permitir a padronização do teste. A fertilização foi feita pela mistura de $10 \mathrm{ml}$ de sêmen de cada um dos 24 machos com $5 \mathrm{~g}$ de óvulos, possibilitando a avaliação do sêmen fresco (dia 1) até aquele armazenado por seis dias. Após a fertilização, os ovos foram colocados em incubadoras de 1,5 $\mathrm{L}$ adaptadas para esta finalidade e contando com sistema de aeração e controle de temperatura. As mesmas 24 alíquotas de sêmen foram armazenadas por mais seis dias e utilizadas para a fertilização no $12^{\circ}$ dia, sendo mantidas sob refrigeração $(5,7 \pm$ $1,2^{\circ} \mathrm{C}$ ) durante todo o período. No $12^{\circ}$ dia foram capturadas outras cinco fêmeas $(639 \pm 224$ g), sendo repetidos os procedimentos descritos anteriormente. Essa metodologia foi utilizada para evitar a captura excessiva de peixes durante os 12 dias e evitar o número excessivo de incubadoras num mesmo momento, possibilitando, contudo, a obtenção desse parâmetro para o período de 12 dias. A taxa de fertilização foi determinada 15-20 horas após a união dos gametas. A estimativa da taxa de fertilização foi obtida pela contagem relativa de ovos fertilizados e não fertilizados feita em amostras de cada incubadora.

Durante 12 dias foi determinado diariamente o tempo de mortalidade do espermatozóide em microscópio óptico (aumento 400X), sendo cronometrado seu tempo de atividade desde a sua ativação com uma gota de água até o momento em que era observada redução da movimentação dos espermatozóides para aproximadamente 10-20\%. Também foram produzidas diariamente lâminas com extensões de sêmen corados com eosina e nigrosina (coloração supravital) para a avaliação da porcentagem de espermatozóides vivos. Essas lâminas foram analisadas em microscópio de contraste de fases (aumento 1200X), sendo feita a contagem de espermatozóides vivos corados pela nigrosina e mortos corados pela eosina e determinando-se a porcentagem de sobrevivência de cada lâmina.

O delineamento experimental foi inteiramente casualisado, sendo os resultados submetidos à análise de variância e teste de Tukey ao nível de 5\% de probabilidade.

\section{Resultados e discussão}

Embora técnicas de estocagem de sêmen sejam pouco utilizadas em estações de reprodução de peixes no Brasil, são muitos os trabalhos científicos que tratam desse assunto para as espécies mais estudadas e criadas comercialmente no mundo, como a truta, Oncorbynchus mykiss, a carpa comum, Cyprinus carpio, o "striped bass", Morone saxatilis, o bagre europeu, Silurus glanis, e outras (NINHAUS-SILVEIRA et al., 2002; HORVÁTH et al., 2003; SHUYANG HE; WOODS III, 2004; LINHART et al., 2005). Ainda são poucos e incipientes os trabalhos de pesquisa que testaram essas técnicas em nossas espécies nativas, porém alguns já relatam as vantagens do armazenamento sob refrigeração (MARQUES; GODINHO, 2004; MURGAS et al., 2004).

A maioria das pesquisas envolvendo o armazenamento do sêmen para uso futuro utiliza métodos de criopreservação em nitrogênio líquido. Fogli da Silveira et al. (1990) registraram taxa de fertilização de 21,07\% para o sêmen de pacu, Piaractus mesopotamicus, armazenado em nitrogênio líquido $\left(-196^{\circ} \mathrm{C}\right)$ por 12 meses. Durante o armazenamento em nitrogênio líquido, muitos autores sugerem o uso de criopreservantes no intuito de aumentar a viabilidade do espermatozóide bem como o tempo de armazenamento (CHEN et al., 2004; BILLARD et al., 2004). Alguns autores apontam ainda a adição de antibióticos visando evitar contaminação bacteriológica do sêmen, prolongando o tempo de armazenamento sob congelamento (CACOT et al., 2003; BILLARD et al., 2004; RURANGWA et al., 2004).

O resfriamento do sêmen não permite seu armazenamento por período tão prolongado quanto o congelamento, porém é uma técnica mais simples e de baixo custo que não exige a utilização de criopreservantes ou antibióticos e que pode ser utilizada em qualquer laboratório de reprodução de peixe. No presente trabalho, mesmo não utilizando diluentes ou preservantes durante o armazenamento do sêmen do jundiá, foram registrados resultados animadores após 12 dias, sugerindo a viabilidade do armazenamento sob refrigeração do sêmen desta espécie.

O tempo médio de motilidade do espermatozóide do jundiá decresceu continuamente ao longo do período experimental, sendo observados valores que variaram entre 55,7 a 16,8 segundos. Comparando-se com o valor inicial (dia 1), foram registradas reduções significativas $(\mathrm{p}<0,05)$ apenas a partir do oitavo dia (FIGURA 1). 


\section{FIGURA 1 - Tempo de motilidade de espermatozóides do sêmen de jundiá Rbamdia quelen armazenado por 12 dias sob refrigeração. $N=4$.}

Figure 1 - Motility (seconds) of semen spermatozoa of jundia, Rhamdia quelen, storage for 12 days under refrigeration. $\mathrm{N}-4$.

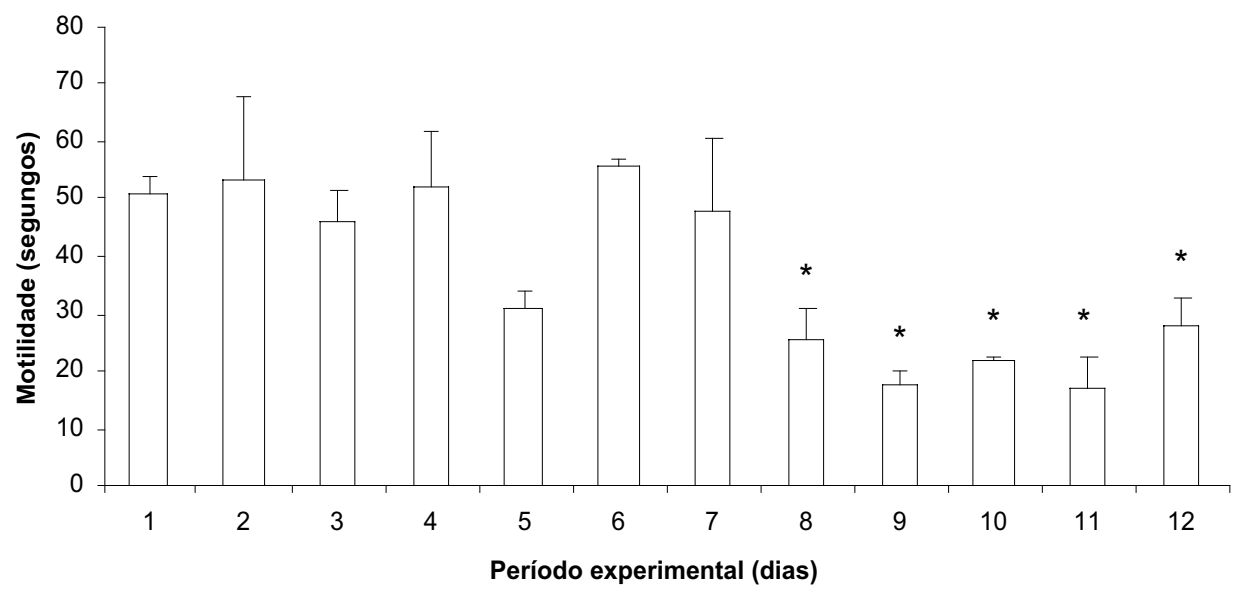

Os valores de motilidade encontrados para o jundiá mostraram a viabilidade do uso do sêmen dessa espécie após refrigeração, corroborando resultados encontrados por Mansour et al. (2002) com bagre africano, Clarias gariepinus, que registraram valores de motilidade do sêmen de 75\% (fresco) até $25 \%$ após 4 dias de armazenamento a $4^{\circ} \mathrm{C}$. Rurangwa et al. (2004) conseguiram observar motilidade do sêmen do bagre americano, Ictalurus puctatus, após 10 dias de armazenamento sob refrigeração, quando foram empregados antibióticos como diluentes. Murgas et al. (2004) apontam para as vantagens do uso de diluentes durante o armazenamento sob refrigeração $\left(4^{\circ} \mathrm{C}\right)$ do sêmen da piracanjuba, Brycon orbignyanus, despertando novas perspectivas de estudos nessa área para nossas espécies nativas testando diluentes e conservantes.

O armazenamento do sêmen sob refrigeração, apesar de não prolongar a vida útil do es- permatozóide pelo mesmo tempo permitido pela técnica de criopreservação, possibilita aumento significativo no tempo de motilidade quando comparado ao sêmen exposto à temperatura ambiente. Para fins de comparação, Luz et al. (2001) concluíram que o sêmen do suruvi, Steindachneridion scripta, não apresenta mais motilidade após 12 horas quando armazenado em temperatura ambiente $\left(25^{\circ} \mathrm{C}\right)$.

Adicionalmente aos resultados de motilidade encontrados nesse estudo, a taxa de sobrevivência dos espermatozóides do jundiá também enfatiza a possibilidade do uso dessa técnica de estocagem do sêmen. A taxa de sobrevivência dos espermatozóides decresceu continuamente durante o período experimental, iniciando em $74,5 \%$ (dia 1) e atingindo $15,5 \%$ ao final de 12 dias. Porém, somente a partir do $5^{\circ}$ dia foram registradas diferenças significativas $(\mathrm{P}<0,05)$ quando comparado ao sêmen fresco (FIGURA 2). 
FIGURA 2 - Taxa de sobrevivência de espermatozóides do sêmen de jundiá Rbamdia quelen armazenado por 12 dias sob refrigeração. $\mathrm{N}=4$.

Figure 2 - Survival rate (\%) of jundia, Rhamdia quelen, spermatozoa storage for 12 days under refrigeration. $\mathrm{N}-4$.

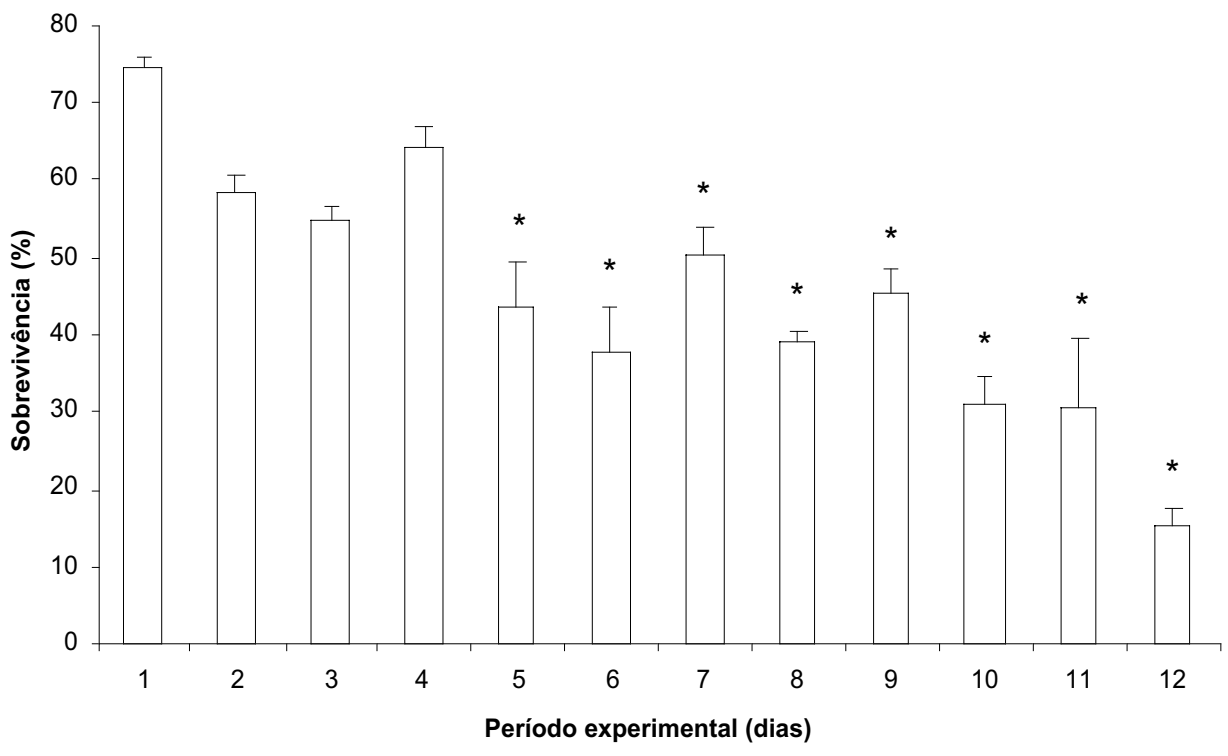

Mesmo ocorrendo problemas técnicos que prejudicaram o pleno desenvolvimento do ensaio com as incubadoras, foi possível registrar taxas de fertilização superiores a 50\% utilizando sêmen armazenado por 12 dias sob refrigeração, enfatizando o potencial de utilização dessa técnica simples de armazenamento em laboratórios comerciais de reprodução do jundiá. Vermeirssen et al. (2004) também obtiveram bons resultados no armazenamento do sêmen do "Atlantic halibut", Hippoglossus hippoglossus, por 20, 40 e 68 dias sob refrigeração (6$6,5^{\circ} \mathrm{C}$ ) sem a adição de diluentes ou criopreservantes, obtendo taxas de fertilização supe-riores a 40\%. Adicionando diluente contendo antibiótico ao sêmen de "paddlefish" Polyodon spathula, Brown e Mims (1995) obtiveram taxas de fertilização superiores a $70 \%$ após 25 dias armazenados a $1^{\circ} \mathrm{C}$.

\section{Conclusões}

O armazenamento sob refrigeração traz muitas vantagens durante os trabalhos de reprodução artificial de peixes, possibilitando a redução de custos com a manutenção do plantel de reprodutores, bem como minimizando os inconvenientes causados pela falta de sincronia repro- dutiva entre os sexos durante o período de reprodução e permitindo a otimização de recursos envolvidos durante os procedimentos de reprodução artificial em laboratório. O presente trabalho sugere a viabilidade de utilização racional do sêmen do jundiá armazenado sob resfriamento e enfatiza a necessidade de estudos adicionais sobre aplicação dessa técnica para outras espécies nativas, bem como para avaliação da adição de diluentes e conservantes para a preservação do sêmen por período mais prolongado.

\section{Agradecimentos}

Os autores agradecem à Pontifícia Universidade Católica do Paraná - PUCPR - e o Conselho Nacional de Desenvolvimento Científico e Tecnológico - CNPQ - pelo apoio financeiro imprescindível à realização deste trabalho.

\section{Referências}

BILLARD, R, et al. Cryopreservation and short-term storage of sturgeon sperm. Aquaculture, v. 236, p. 1-9, 2004. 
BROWN, G. G.; MIMS, S. D. Storage, transportation, and fertility of undiluted and diluted paddlefish milt. Progressive Fish-Culturist, v. 57, p. 64- 69, 1995.

CACOT, P., et al. Induced spermiation and milt management in Pangasius bocourti (Sauvage, 1880).

Aquaculture, v. 215, p. 67-77, 2003.

CARNEIRO, P. C. F., et al. Jundiá: Um grande peixe para a região Sul. Panorama da Aqüicultura, v. 12, p. 41-46, 2002.

CHEN, S. L., et al. Cryopreservation of sperm from turbot (Scophthalmus maximus) and application to large-scale fertilization. Aquaculture, v. 236, p. 547-556, 2004.

FOGLI DA SILVEIRA, W. F., et al. Avaliação espermática, preservação criogênica e fertilidade do sêmen do pacu, Piaractus mesopotamicus (HOSEMBERG 1887), proveniente de reprodução induzida. Boletim do Instituto de Pesca, v. 17, p. 1-13, 1990.

HORVÁTH, A.; MISKOLCZI, E.; URBÁNYI, B. Cryopreservation of common carp sperm. Aquatic Living Resources, v. 16, p. 457-460, 2003.

LINHART, O., et al. Cryopreservation of European catfish Silurus glanis sperm: Sperm motility, viability, and hatching success of embryos. Cryobiology, v. 51, p. 250-261, 2005.

LUZ, R. K., et al. Avaliação qualitativa e quantitativa do sêmen de suruvi, Steindachneridion scripta (PIMELODIDAE). Boletim do Instituto de Pesca, v. 27, p. 39-42, 2001.

MANSOUR, N.; LAHNSTEINER, F.; PATZNER, R. A. The spermatozoon of the African catfish: fine structure, motility, viability and its behaviour in seminal vesicle secretion. Journal of Fish Biology, v. 60, p. 545-560, 2002.
MARQUES, S.; GODINHO, H. P. Short-term Cold Storage of Sperm from Six Neotropical Characiformes Fishes. Brazilian Archives of Biology and Technology, v. 47, p. 799-804, 2004.

MURGAS, L. D. S., et al. VIABILIDADE Espermática do sêmen de piracanjuba (Brycon orbignyanus) resfriado a $4^{\circ} \mathrm{C}$. Revista Brasileira de Zootecnia, v. 33, p. 1361-1365, 2004.

NINHAUS-SILVEIRA, A., et al. Cryopreservation of rainbow trout semen: Diluent, straw and the vapor column. Boletim do Instituto de Pesca, v. 28, p. 135-139, 2002.

RURANGWA, E., et al. The measurement of sperm motility and factors affecting sperm quality in cultured fish. Aquaculture, v. 234, p. 1-28, 2004.

SHUYANG HE, L., WOODS III, C. Changes in motility, ultrastructure, and fertilization capacity of striped bass Morone saxatilis spermatozoa following cryopreservation. Aquaculture, v. 236, p. 677-686, 2004.

VERMEIRSSEN, E. L. M., et al. Fertility and motility of sperm from Atlantic halibut (Hippoglossus bippoglossus) in relation to dose and timing of gonodotrophin-releasing hormone agonist implant. Aquaculture, v. 234, p. 547-567, 2004.

Recebido: 02/09/2005 Aprovado: 20/12/2005 